\title{
Application of different anesthetic methods in coronary artery bypass grafting and the effect on postoperative outcome
}

\author{
YAFEI SHI ${ }^{1}$ and WENZHU WANG ${ }^{2}$ \\ Departments of ${ }^{1}$ Cardiac Surgery and ${ }^{2}$ Anesthesiology, Jining No. 1 People's Hospital, Jining, Shandong 272000, P.R. China
}

Received April 30, 2018; Accepted November 8, 2018

DOI: $10.3892 /$ etm.2018.6993

\begin{abstract}
Application of different anesthetic methods in coronary artery bypass grafting and its effect on postoperative outcome were explored. Ninety-four patients undergoing coronary artery bypass grafting in Jining No. 1 People's Hospital from March 2017 to February 2018 were randomly divided into the control and observation groups. The control group was anesthetized by fentanyl and propofol. The observation group was anesthetized by sevoflurane combined anesthesia. The mean heart rates (HR), mean arterial pressure (MAP), systemic vascular resistance index (SVRI) and cardiac index $(\mathrm{CI})$ in the two groups were compared. The levels of $\beta$ endorphin ( $\beta$-EP) and malondialdehyde (MDA) in patients were examined. Adverse reactions in the two groups were compared. The enzyme-linked immunosorbent assay (ELISA) was used to detect the changes of serum inflammatory factors. The prognosis of the two groups was analyzed and compared. MoCA and MMSE scale were used to evaluate postoperative cognitive function in the two groups. The levels of $\beta$-EP and MDA in the two groups during operation were higher than those before operation $(\mathrm{P}<0.05)$. On the third, fifth and seventh day after operation, the CRP, TNF- $\alpha$ and IL- 6 levels of the two groups increased significantly compared to those before operation $(\mathrm{P}<0.05)$. The eating time and out of bed time in the observation group were significantly earlier than those in the control group, and the length of stay in the observation group was significantly shorter than that in the control group $(\mathrm{P}<0.05)$. On the first day after operation, the scores of MoCA and MMSE in the observation group were better than those in the control group $(\mathrm{P}<0.05)$. The two different anesthetic methods can maintain the perioperative hemodynamic stability of coronary artery bypass patients, but sevoflurane intravenous-inhalation combined anesthesia can effectively
\end{abstract}

Correspondence to: Dr Wenzhu Wang, Department of Anesthesiology, Jining No. 1 People's Hospital, 99 Shixian Road, Gaoxin, Jining, Shandong 272000, P.R. China

E-mail: ewe9gg@163.com

Key words: sevoflurane intravenous-inhalation combined anesthesia, Coronary artery bypass grafting, inflammatory factors, cognitive dysfunction adjust the $\beta$-EP in the body, and reduce the oxidative stress response, which is favorable for postoperative outcome.

\section{Introduction}

Coronary artery bypass grafting $(\mathrm{CABG})$ is one of the main methods for surgical treatment of heart disease. Most patients undergoing $\mathrm{CABG}$ are in severe condition. They all have different degrees of cardiac damage, and are particularly sensitive to anesthetic drugs, complications are easy to occur and are affecting their postoperative outcome $(1,2)$. Off-pump coronary artery bypass grafting (OPCABG) can effectively reduce postoperative serious complications, so it has been widely used in clinical practice, but OPCABG will bring obvious stress response to patients, cutting the sternum in the operation especially increases stress response, leading to hemodynamic changes in patients, and the emergence of inflammatory reactions, easily lead to systemic inflammatory response syndrome. Anesthetic drugs can also lead to neurological and cognitive functional complications $(3,4)$. Malondialdehyde (MDA) is the final metabolite of oxidative stress and can reflect the level of oxidative stress (5). $\beta$-endorphin ( $\beta$-EP) can play an important role in analgesia (6). Sevoflurane is a new type of inhalation anesthetic gas, it can reduce myocardial ischemia/reperfusion injury, and play a protective role on the myocardium, and has a role on internal environment changes and the course of disease of CABG perioperative patients (7). In this study, OPCABG patients were given anesthesia by different anesthesia methods to explore their impact on hemodynamics, inflammation, and postoperative outcomes.

\section{Patients and methods}

General Information. During the period from March 2017 to February 2018, 94 patients undergoing coronary artery bypass surgery in Jining No. 1 People's Hospital (Jining, China) were included. Inclusion criteria were: i) heart function at Class II-III according to New York Heart Association; ii) all performed OPCABG and complete medical records and iii) signed informed consent. Exclusion criteria were: i) severe renal insufficiency, history of heart failure, and coagulation dysfunction; ii) brain organic disease and severe physical disease and iii) drug allergies. Random number table method was used to divide patients into the control (47 cases) and observation groups (47 cases). There was no significant 
Table I. Baseline data of two groups of patients.

\begin{tabular}{lcccr}
\hline Items & $\begin{array}{c}\text { Observation group } \\
\mathrm{n}=47\end{array}$ & $\begin{array}{c}\text { Control group } \\
\mathrm{n}=47\end{array}$ & $\mathrm{t} / \chi^{2}$ value & P-value \\
\hline Sex (Male/Female) & $29 / 18$ & $27 / 20$ & 0.044 & 0.833 \\
Age (year) & $20-38$ & $20-40$ & & 0.652 \\
Average age (year) & $29.46 \pm 6.42$ & $28.85 \pm 6.63$ & 0.453 & 0.657 \\
BMI (kg/m ${ }^{2}$ ) & $22.03 \pm 1.45$ & $22.16 \pm 1.38$ & 0.445 & 0.673 \\
NYHA heart function (n,\%) & $17(36.17)$ & & & 0.178 \\
Class II & $30(63.83)$ & $20(42.55)$ & & 0.746 \\
Class III & $201.54 \pm 13.17$ & $202.43 \pm 13.36$ & 0.325 & \\
Operation time (min) & & & & \\
\hline
\end{tabular}

difference in general data between the two groups $(\mathrm{P}>0.05)$, and the data were comparable (Table I).

The study was approved by the Ethics Committee of Jining No. 1 People's Hospital. Patients who participated in this study, signed the informed consent and had complete clinical data.

Anesthesia method. Both groups of patients fasted for $8 \mathrm{~h}$ before surgery. After entering the operating room, the mask was given pure oxygen $(6 \mathrm{l} / \mathrm{min})$ to make the blood oxygen saturation above $98 \%$, and the patient's peripheral veins were opened. Patients in the control group were given fentanyl $(5 \mu \mathrm{g} / \mathrm{kg})$ and vecuronium bromide $(0.1 \mathrm{mg} / \mathrm{kg})$ for induction of anesthesia. If BIS value was below 55, patients were intubated and connected to the ventilator (respiration rate: 12-15 times/min, inhalation ratio was $1: 2$, tidal volume was $8-9 \mathrm{ml} / \mathrm{kg})$, and propofol $(3 \mathrm{mg} / \mathrm{kg} / \mathrm{h})$ and fentanyl $(5 \mu \mathrm{g} / \mathrm{kg} / \mathrm{h})$ were used to maintain anesthesia.

In the observation group, the induction of anesthesia was the same as in the control group. Inhalation of sevoflurane (concentration 3 to $4 \%$ ) continued after tracheal intubation, and sevoflurane was adjusted according to changes in the depth of anesthesia (BIS value).

Detection of related indicators. Serum MDA concentration was measured by thiobarbituric acid (TBA) before and during surgery. $\beta$-EP levels in serum were detected by enzymelinked immunosorbent assay (ELISA). The kits were all provided by Nanjing Bioengineering Research, the operation was in strict accordance with the instructions, the OD value was measured by a microplate reader (Bio-Rad Laboratories, Inc., Hercules, CA, USA) at a wavelength of $532 \mathrm{~nm}$, and the MDA content in the serum was calculated. The OD value was read using a microplate reader (Bio-Rad Laboratories, Inc.) at a wavelength of $450 \mathrm{~nm}$, and the corresponding $\beta$-EP concentration level was calculated.

Peripheral venous blood $(4 \mathrm{ml})$ was collected before surgery and 3,5, and 7 days after surgery. The sample was centrifuged at $3,000 \times \mathrm{g} 4^{\circ} \mathrm{C}$ for $15 \mathrm{~min}$ and the supernatant was stored at $-70^{\circ} \mathrm{C}$. The levels of CRP, TNF- $\alpha$ and IL- 6 were detected by ELISA. The kits were all provided by American RB. They were operated strictly in accordance with the instructions. OD values were read at a wavelength of $450 \mathrm{~nm}$ using a microplate reader to calculate the concentrations of CRP, TNF- $\alpha$ and IL-6.
Evaluation methods. Mean heart rate (HR), mean arterial pressure (MAP), Systemic Vascular Resistance Index (SVRI) and Heart Index (CI) in the two groups immediately before induction of anesthesia (T1), 2 min after sawing the sternum (T2), after the start of bypass of the coronary artery (T3), and at the end of bypass (T4) were measured.

The level of MDA was measured by TBA method and $\beta$-EP level was measured by ELISA. The inflammatory factors (CRP, TNF- $\alpha$, IL-6) were measured by ELISA before and 3, 5, and 7 days after operation. Adverse reactions were observed in both groups, including nausea and vomiting, hypoxemia, delay in wakefulness, and postoperative agitation. Postoperative eating time, ambulation time and hospital stay were observed and recorded.

Cognitive function was assessed using the Montreal Cognitive Assessment (MoCA) Scale (Spatial and Executive Ability, Memory, Attention, Naming, Language, Delayed Recall, Abstract Thinking, and Directional Rating in 8 Fields) (8) and Mini Mental State Examination (MMSE) Scales (score, language, recall, attention and computational power) (9) 1 day before and after surgery. The scores were negatively correlated with the degree of cognitive impairment.

Statistical analysis. The data were processed using SPSS 19.0 (SPSS Inc., Chicago, IL, USA) software. Measurement data were expressed as mean \pm standard deviation and t-test was used. The enumeration data were expressed as a rate, and ANOVA was used for multiple comparisons with Tukey's test. $\mathrm{P}<0.05$ for the difference was statistically significant.

\section{Results}

Comparison of hemodynamic parameters between different anesthesia patients. There were no significant differences in HR, MAP, SVRI and CI between the two groups at different times $(\mathrm{P}>0.05)$ (Table II).

Comparison of the levels of $\beta-E P$ and MDA in both groups. Both $\beta$-EP and MDA in the two groups during operation were higher than before operation. The level of $\beta$-EP in the observation group was higher than that in the control group, and the level of MDA was lower in the observation group than in the control group $(\mathrm{P}<0.05)$ (Table III). 
Table II. Comparison of hemodynamic parameters at different time periods.

\begin{tabular}{|c|c|c|c|c|c|c|}
\hline Indexes & Group & No. of cases & $\mathrm{T} 1$ & $\mathrm{~T} 2$ & $\mathrm{~T} 3$ & $\mathrm{~T} 4$ \\
\hline \multirow[t]{2}{*}{ HR (time) } & Observation & 47 & $75.53 \pm 3.36$ & $74.85 \pm 3.62$ & $68.15 \pm 3.35$ & $71.82 \pm 3.73$ \\
\hline & Control & 47 & $75.08 \pm 3.72$ & $75.14 \pm 3.53$ & $67.93 \pm 3.38$ & $71.17 \pm 3.45$ \\
\hline \multirow[t]{2}{*}{ MAP (mmHg) } & Observation & 47 & $77.16 \pm 3.48$ & $74.82 \pm 3.32$ & $72.63 \pm 3.29$ & $78.08 \pm 3.37$ \\
\hline & Control & 47 & $77.13 \pm 3.36$ & $74.76 \pm 3.38$ & $72.45 \pm 3.32$ & $78.14 \pm 3.35$ \\
\hline \multirow[t]{2}{*}{ SVRI (dynes-s/cm5/m²) } & Observation & 47 & $2,638.78 \pm 91.42$ & $2,575.48 \pm 84.35$ & $2,734.56 \pm 93.37$ & $2,632.92 \pm 92.39$ \\
\hline & Control & 47 & $2,636.82 \pm 91.35$ & $2,574.53 \pm 83.34$ & $2,735.68 \pm 92.35$ & $2,635.87 \pm 91.56$ \\
\hline \multirow[t]{2}{*}{$\mathrm{CI}\left(1 / \mathrm{min} \cdot \mathrm{m}^{2}\right)$} & Observation & 47 & $2.08 \pm 0.52$ & $1.94 \pm 0.45$ & $2.36 \pm 0.57$ & $2.32 \pm 0.59$ \\
\hline & Control & 47 & $2.02 \pm 0.55$ & $1.92 \pm 0.44$ & $2.38 \pm 0.58$ & $2.37 \pm 0.56$ \\
\hline
\end{tabular}

Table III. Comparison of $\beta$-EP and MDA levels in the two groups.

\begin{tabular}{|c|c|c|c|c|c|c|c|c|}
\hline \multirow[b]{2}{*}{ Groups } & \multicolumn{2}{|c|}{$\beta-\mathrm{EP}(\mathrm{pg} / \mathrm{ml})$} & \multirow[b]{2}{*}{ t value } & \multirow[b]{2}{*}{ P-value } & \multicolumn{2}{|c|}{ MDA (nmol/l) } & \multirow[b]{2}{*}{ t value } & \multirow[b]{2}{*}{ P-value } \\
\hline & Preoperative & Intraoperative & & & Preoperative & Intraoperative & & \\
\hline Observation & $106.82 \pm 7.72$ & $192.73 \pm 6.82$ & 57.176 & $<0.001$ & $1.26 \pm 0.53$ & $3.48 \pm 1.02$ & 13.240 & $<0.001$ \\
\hline Control & $106.72 \pm 7.67$ & $151.32 \pm 6.73$ & 29.965 & $<0.001$ & $1.25 \pm 0.65$ & $6.24 \pm 1.07$ & 27.325 & $<0.001$ \\
\hline t value & 0.063 & 29.629 & & & 0.082 & 12.800 & & \\
\hline P-value & 0.950 & $<0.001$ & & & 0.935 & $<0.001$ & & \\
\hline
\end{tabular}

Table IV. Comparison of adverse reactions after surgery in the two groups (n,\%).

\begin{tabular}{lccccc}
\hline Groups & No. of cases & Nausea and vomiting & Hypoxemia & Postoperative agitation & Delay in wakefulness \\
\hline Observation & 47 & $3(6.38)$ & $1(2.13)$ & $1(2.13)$ & $2(4.26)$ \\
Control & 47 & $4(8.51)$ & $2(4.26)$ & $2(4.26)$ & $3(6.38)$ \\
$\chi^{2}$ value & & 0.001 & 0.002 & 5.547 & 0.001 \\
P-value & 0.999 & 0.982 & 0.019 & 0.999 \\
\hline
\end{tabular}

Table V. Comparison of CRP levels in different periods of patients in the two groups (mg/l).

\begin{tabular}{|c|c|c|c|c|c|}
\hline Groups & No. of cases & Preoperative & Day 3 & Day 5 & Day 7 \\
\hline Observation & 47 & $7.58 \pm 3.63$ & $69.04 \pm 4.53^{\mathrm{a}}$ & $51.28 \pm 4.27^{\mathrm{a}}$ & $22.65 \pm 3.83^{\mathrm{a}}$ \\
\hline Control & 47 & $7.62 \pm 3.72$ & $82.26 \pm 4.62^{\mathrm{a}}$ & $68.75 \pm 4.48^{\mathrm{a}}$ & $33.57 \pm 3.77^{\mathrm{a}}$ \\
\hline t value & & 0.053 & 14.007 & 19.352 & 13.930 \\
\hline P-value & & 0.958 & $<0.001$ & $<0.001$ & $<0.001$ \\
\hline
\end{tabular}

${ }^{\mathrm{a}} \mathrm{P}<0.05$, compared to the preoperative group.

Comparison of adverse reactions after surgery. There was no significant difference in the incidence of nausea and vomiting, hypoxemia, postoperative restlessness and delayed awakening between the two groups ( $\mathrm{P}>0.05)$, as shown in Table IV.

Comparison of inflammation index. There was no significant difference in CRP, TNF- $\alpha$, and IL- 6 between the two groups before surgery $(\mathrm{P}>0.05)$. There was a significant increase after surgery in the two groups, and the control group was more significant than the observation group $(\mathrm{P}<0.001)$ (Tables V-VII).

Comparison of the outcome of the two groups. The eating time and the time of getting out of bed in the observation group were significantly earlier than those in the control group, and the length of stay in the observation group was significantly shorter than that in the control group $(\mathrm{P}<0.05)$ (Table VIII). 
Table VI. Comparison of the patient TNF- $\alpha$ levels in different periods of in the two groups (ng/l).

\begin{tabular}{|c|c|c|c|c|c|}
\hline Groups & No. of cases & Preoperative & Day 3 & Day 5 & Day 7 \\
\hline Observation & 47 & $6.36 \pm 3.53$ & $83.73 \pm 5.14^{\mathrm{a}}$ & $55.27 \pm 4.28^{\mathrm{a}}$ & $26.38 \pm 3.46^{\mathrm{a}}$ \\
\hline Control & 47 & $6.41 \pm 3.72$ & $95.25 \pm 5.65^{\mathrm{a}}$ & $68.75 \pm 4.19^{a}$ & $35.43 \pm 3.75^{\mathrm{a}}$ \\
\hline t value & & 0.067 & 10.340 & 15.429 & 12.160 \\
\hline P-value & & 0.947 & $<0.001$ & $<0.001$ & $<0.001$ \\
\hline
\end{tabular}

${ }^{\mathrm{a}} \mathrm{P}<0.05$, compared to the preoperative group.

Table VII. Comparison of the patient IL-6 levels in different periods in the two groups (ng/l).

\begin{tabular}{|c|c|c|c|c|c|}
\hline Groups & No. of cases & Preoperative & Day 3 & Day 5 & Day 7 \\
\hline Observation & 47 & $15.42 \pm 3.84$ & $112.13 \pm 6.16^{\mathrm{a}}$ & $98.56 \pm 5.25^{\mathrm{a}}$ & $58.62 \pm 4.68^{a}$ \\
\hline Control & 47 & $15.37 \pm 3.72$ & $127.54 \pm 6.74^{\mathrm{a}}$ & $109.63 \pm 5.42^{\mathrm{a}}$ & $69.54 \pm 4.65^{\mathrm{a}}$ \\
\hline t value & & 0.064 & 11.570 & 10.058 & 11.348 \\
\hline P-value & & 0.949 & $<0.001$ & $<0.001$ & $<0.001$ \\
\hline
\end{tabular}

${ }^{\mathrm{a}} \mathrm{P}<0.05$, compared to the preoperative group.

Table VIII. Postoperative outcomes of the two groups of patients.

\begin{tabular}{lcccc}
\hline Groups & No. of cases & Time to taking food $(\mathrm{h})$ & Time of getting out of bed (h) & The length of stay (days) \\
\hline Observation & 47 & $30.83 \pm 3.72$ & $37.38 \pm 4.26$ & $13.32 \pm 1.25$ \\
Control & 47 & $45.15 \pm 3.65$ & $49.56 \pm 4.38$ & $17.63 \pm 1.47$ \\
t value & & 18.837 & 13.666 & 15.313 \\
P-value & $<0.001$ & $<0.001$ & $<0.001$ \\
\hline
\end{tabular}

Table IX. Comparison of MoCA and MMSE scores in the two groups.

\begin{tabular}{|c|c|c|c|c|c|c|c|c|}
\hline \multirow[b]{2}{*}{ Groups } & \multicolumn{2}{|c|}{ MoCA (score) } & \multirow[b]{2}{*}{$\mathrm{t}$ value } & \multirow[b]{2}{*}{ P-value } & \multicolumn{2}{|c|}{ MMSE (score) } & \multirow[b]{2}{*}{$\mathrm{t}$ value } & \multirow[b]{2}{*}{ P-value } \\
\hline & $\begin{array}{c}1 \text { day } \\
\text { preoperative }\end{array}$ & $\begin{array}{c}1 \text { day } \\
\text { postoperative }\end{array}$ & & & $\begin{array}{c}1 \text { day } \\
\text { preoperative }\end{array}$ & $\begin{array}{c}1 \text { day } \\
\text { postoperative }\end{array}$ & & \\
\hline Observation & $28.83 \pm 1.52$ & $26.95 \pm 1.72$ & 7.203 & $<0.001$ & $30.48 \pm 1.53$ & $26.38 \pm 1.56$ & 11.613 & $<0.001$ \\
\hline Control & $28.82 \pm 1.63$ & $25.32 \pm 1.74$ & 9.718 & $<0.001$ & $29.97 \pm 1.61$ & $23.23 \pm 1.57$ & 18.512 & $<0.001$ \\
\hline t value & 0.079 & 4.189 & & & 0.755 & 9.623 & & \\
\hline P-value & 0.882 & 0.001 & & & 0.572 & $<0.001$ & & \\
\hline
\end{tabular}

Comparison of the MoCA and MMSE scores of the two groups. The MoCA and MMSE scores of both groups after surgery were lower than those before surgery, and the decrease in the observation group was lower than in the control group $(\mathrm{P}<0.05)$ (Table IX).

\section{Discussion}

Off-pump coronary artery bypass grafting (OPCABG) is a cardiac surgery method developed in recent years, it can avoid cardiopulmonary bypass, so the incidence of serious complications after surgery is greatly reduced, and it is widely recognized in the clinic. When OPCABG is performed, it needs to be performed with the heart beating continuously. Therefore, the difficulty of the operation is increased, and the requirement for anesthesia is higher than that of CABG. Therefore, seeking the best anesthesia has a significant importance on the surgical outcome and postoperative outcome of OPCABG patients.

Sevoflurane is a new safe and effective inhalation halogenated volatile anesthetic with the smallest gas partition coefficient. It 
is widely used in cardiac surgery and its effectiveness and safety have been confirmed (10). The results of this study showed that there was no significant difference in perioperative HR, MAP, SVRI, and CI between the two groups $(\mathrm{P}>0.05)$. This shows that the combination of sevoflurane inhalation and combined anesthesia does not cause abnormal hemodynamic changes in the patient compared with routine anesthesia.

OPCABG is one of the most common major cardiac surgery operations. Perioperative patients can cause severe stress reactions. Especially when the sternum was cut and the aortic wall was clamped, the strong stimulation of the injury site was the main cause of the perioperative stress response of OPCABG. How to suppress this strong stimulation and regulate the patient's stress response is one of the main tasks of anesthesia (11). MDA is an oxidative stress product with strong cytotoxicity, and its concentration level directly reflects the rate and intensity of lipid peroxidation in vivo (12). $\beta$-EP is an inhibitory transmitter that regulates pain pathways and plays an important role in analgesia (13). The results of this study showed that both $\beta$-EP and MDA were elevated in the two groups during the operation compared with before surgery. The level of $\beta$-EP in the observation group was higher than that in the control group, and the level of MDA was lower in the observation group than in the control group $(\mathrm{P}<0.05)$. It is because during OPCABG, surgical operations and anesthetic drug stimulation lead to the patient's stress response, oxygen free radicals are damaged, an imbalance occurs in the body's redox reaction, resulting in oxidative stress, leading to increased MDA levels. In contrast to fentanyl and propofol anesthetics, sevoflurane inhibits the release of sensory-transmitter substance $\mathrm{P}$ and promotes the secretion of large amounts of $\beta$-EP from the pituitary gland, which plays a positive feedback role in the analgesic pathway; sevoflurane can effectively scavenge oxygen free radicals, thereby reducing MDA levels.

The wounds of OPCABG cause systemic stress responses in the patient, altering the body's neuroendocrine-immune regulatory network, and leading to abnormal changes in catechol, which in turn stimulates the massive secretion of inflammatory cytokines (14). CRP is an acute phase reaction protein and is one of the indicators of the inflammatory response (15). TNF- $\alpha$ can initiate and trigger inflammatory reactions that can lead to necrosis of tumor cells, but also has anti-infective and immunomodulatory effects (16). IL-6 is an acute phase reactive lymphocyte factor that can play a diversified role in the inflammatory response (17). The results of this study showed that serum CRP, TNF- $\alpha$, and IL-6 levels were significantly elevated in both groups of patients after surgery, and the increase was significantly higher in the control group than in the observation group $(\mathrm{P}<0.05)$. This is because OPCABG, as a major operation, is combined with immune response in order to release all kinds of inflammatory mediators. Therefore, the levels of CRP, TNF- $\alpha$ and IL- 6 will increase, sevoflurane can reduce ischemia/reperfusion injury and protect the myocardium, thus reducing myocardial oxygen consumption, without reducing the blood flow of the myocardium and alleviating the accumulation of neutrophils in the body, the effect of inhibiting various inflammatory factors can be achieved.

After major operations, especially after anesthesia, patients develop intellectual disabilities such as social skills, memory, and orientation disability (18). The various discomforts in the recovery after OPCABG may lead to excessive sympathetic nerve tension in the patient and sensitization of the central nervous system. With the release of a large number of inflammatory factors, it migrates through the blood-brain barrier and causes an inflammatory reaction in the hippocampus of the brain, therefore, generating cognitive dysfunction (19). The results of this study showed that both MoCA and MMSE scores decreased after surgery in both groups, and that the decrease in the observation group was significantly lower $(\mathrm{P}<0.05)$ compared with the control group. This is because anesthesia causes neuronal morphology and biological changes, leading to loss and apoptosis of neurons, easy to produce cognitive dysfunction, and sevoflurane has the advantages of no irritating stimuli, rapid induction of awakening, easy control of the depth of anesthesia, prevents intracellular $\mathrm{Ca}^{2+}$ overload to reduce or avoid neuronal necrosis, and plays a protective role in dealing with ischemic neuronal injury, thereby improving the expression of neurotrophic factors in the dentate gyrus of the hippocampus, and reducing the degree of inflammatory reactions in the hippocampus, thereby reducing the incidence of cognitive dysfunction, and has a positive promotion role in the rapid recovery of patients (20).

In summary, compared with fentanyl and propofol anesthetic drugs, sevoflurane inhalation combined anesthesia has a significant effect on reducing stress response and reducing postoperative inflammatory reactions and cognitive dysfunction. It is beneficial to the patient's postoperative outcome and has certain clinical application value.

\section{Acknowledgements}

Not applicable.

\section{Funding}

No funding was received.

\section{Availability of data and materials}

The datasets used and/or analyzed during the present study are available from the corresponding author on reasonable request.

\section{Authors' contributions}

YS and WW wrote the manuscript. YS and WW collected the data and analyzed related indicators. WW revised the manuscript. Both authors read and approved the final manuscript.

\section{Ethics approval and consent to participate}

The study was approved by the Ethics Committee of Jining No. 1 People's Hospital (Jining, China). Signed informed consents were obtained from the patients or guardians.

\section{Patient consent for publication}

Not applicable.

\section{Competing interests}

The authors declare that they have no competing interests. 


\section{References}

1. Karaman Y, Abud B, Tekgul ZT, Cakmak M, Yildiz M and Gonullu M: Effects of dexmedetomidine and propofol on sedation in patients after coronary artery bypass graft surgery in a fast-track recovery room setting. J Anesth 29: 522-528, 2015.

2. Mackay JH, Nashef SA, Paprachristofi O and Sharples L: The impact of anesthesiologists on coronary artery bypass graft outcomes. Anesth Analg 122: 1719, 2016.

3. Taggart DP: Off-pump coronary artery bypass grafting (OPCABG) -a 'personal' European perspective. J Thorac Dis 8 (Suppl 10): S829-S831, 2016.

4. Rodés-Cabau J and Puri R: Filtering the truth behind cerebral embolization during transcatheter aortic valve replacement JACC Cardiovasc Interv 8: 725-727, 2015.

5. Zhou F, Sun W and Zhao M: Controlled formation of emulsion gels stabilized by salted myofibrillar protein under malondialdehyde (MDA)-induced oxidative stress. J Agric Food Chem 63: 3766-3777, 2015.

6. Veening JG and Barendregt HP: The effects of beta-endorphin: State change modification. Fluids Barriers CNS 12: 3, 2015.

7. Wen XR, Fu YY, Liu HZ, Wu J, Shao XP, Zhang XB, Tang M, Shi Y, Ma K, Zhang F, et al: Neuroprotection of sevoflurane against ischemia/reperfusion-induced brain injury through inhibiting JNK3/Caspase-3 by enhancing Akt signaling pathway. Mol Neurobiol 53: 1661-1671, 2016.

8. Ciesielska N, Sokołowski R, Mazur E, Podhorecka M, Polak-Szabela A and Kędziora-Kornatowska K: Is the Montreal Cognitive Assessment (MoCA) test better suited than the Mini-Mental State Examination (MMSE) in mild cognitive impairment (MCI) detection among people aged over 60? Metaanalysis. Psychiatr Pol 50: 1039-1052, 2016 (In Polish).

9. Brodaty H, Connors MH, Loy C, Teixeira-Pinto A, Stocks N, Gunn J, Mate KE and Pond CD: Screening for dementia in primary care: A comparison of the GPCOG and the MMSE. Dement Geriatr Cogn Disord 42: 323-330, 2016.

10. Wang WY, Jia LJ, Luo Y, Zhang HH, Cai F, Mao H, Xu WC, Fang JB, Peng ZY, Ma ZW, et al: Location- and subunit-specific NMDA receptors determine the developmental sevoflurane neurotoxicity through ERK1/2 signaling. Mol Neurobiol 53: 216-230, 2016.

11. Ziyaeifard M and Ziyaeifard P: 'Effects of selenium on stress response in coronary artery bypass graft surgery: A clinical trial study'. Anesth Pain Med 7: e45461, 2017.
12. Tang X, Rong G, Bu Y, Zhang S, Zhang M, Zhang J and Liang X: Advanced oxidation protein products induce hypertrophy and epithelial-to-mesenchymal transition in human proximal tubular cells through induction of endoplasmic reticulum stress. Cell Physiol Biochem 35: 816-828, 2015.

13. Bruehl S, Burns JW, Gupta R, Buvanendran A, Chont M, Orlowska D, Schuster E and France CR: Do resting plasma $\beta$-endorphin levels predict responses to opioid analgesics? Clin J Pain 33: 12-20, 2017.

14. Formica F, Broccolo F and Cerrito MG: Minimal extracorporeal circulation and minimally invasive valve operations: Should they be the right combination in the future? Ann Thorac Surg 103: $1038,2017$.

15. Han SS, Kim DK, Kim S, Chin HJ, Chae DW and Na KY: C-reactive protein predicts acute kidney injury and death after coronary artery bypass grafting. Ann Thorac Surg 104: 804-810, 2017.

16. Murdaca G, Spanò F, Contatore M, Guastalla A, Penza E, Magnani $\mathrm{O}$ and Puppo F: Infection risk associated with anti-TNF- $\alpha$ agents: A review. Expert Opin Drug Saf 14: 571-582, 2015.

17. Peng Z, Sun Y, Lv X, Zhang H, Liu C and Dai S: Interleukin-6 levels in women with polycystic ovary syndrome: A systematic review and meta-analysis. PLoS One 11: e0148531, 2016.

18. Nascimento CM, Pereira JR, Pires de Andrade L, Garuffi M, Ayan C, Kerr DS, Talib LL, Cominetti MR and Stella F: Physical exercise improves peripheral BDNF levels and cognitive functions in mild cognitive impairment elderly with different bdnf Val66Met genotypes. J Alzheimers Dis 43: 81-91, 2015.

19. Zou JF, Li JY, Wu XW and Chen SY: Effects of different anesthesia and analgesia on erythrocyte immune function of patients with ovarian benign tumor treated by laparoscopic therapeutic. Xi Bao Yu Fen Zi Mian Yi Xue Za Zhi 26: 1252-1254, 2010 (In Chinese).

20. Zheng JW, Meng B, Li XY, Lu B, Wu GR and Chen JP: $\mathrm{NF}-\kappa \mathrm{B} / \mathrm{P} 65$ signaling pathway: A potential therapeutic target in postoperative cognitive dysfunction after sevoflurane anesthesia. Eur Rev Med Pharmacol Sci 21: 394-407, 2017.

c) (7) $\odot$ This work is licensed under a Creative Commons cc) Attribution-NonCommercial-NoDerivatives 4.0 International (CC BY-NC-ND 4.0) License. 